\title{
Teachers as actors in an educational design research: What is behind the generalized formula?
}

\section{Helén Sterner}

Linnaeus University and Dalarna University, Sweden, Faculty of Mathematics Education

\begin{abstract}
Educational design research provides opportunities for both the theoretical understanding and practical explanations of teaching. In educational design research, mathematics teachers' learning is essential. However, research shows that little consideration is given to teachers and the participation of teachers throughout the entire design process as well as in continued learning. With this in mind, educational teacher-focused design research was used to explore the challenges teachers face, and the opportunities teachers are given when they participate as actors in all the phases of educational design research - designing, teaching, and refining theoretical concepts within the teaching. In this study, the mathematics focus of the design research was generalizations in patterns with Design Principles as the theoretical frame. The results show that the participation of teachers in all the phases of a design process is central for the teachers' learning. Moreover, challenges that the teachers encounter in the classroom provide opportunities and consequences for the continued design process and lead to changes in the teachers' understanding of generalizations. The results also indicate that functional thinking and linear equations contributed to both the teachers' and students' learning about generalizations in patterns.
\end{abstract}

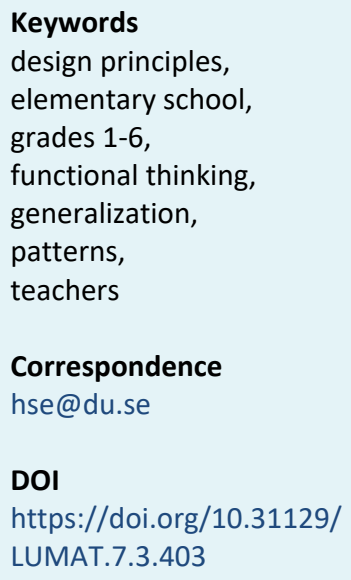

\section{Introduction}

Educational design research provides opportunities for both theoretical and pragmatic orientations and creates opportunities for interventionist methodology and collaboration between researchers and teachers. Several previous studies give creative examples of students learning (e.g., Stephan \& Akyuz, 2012) or give examples of how research teams to design, implement, and refine teaching to improve classroom practice with teachers and develop the theoretical understanding of different classroom phenomena (e.g., Stephan, 2015; Stephan \& Akyuz, 2012). The results from previous design research studies have advocated theoretical solutions for practices. However, implementing theoretical concepts into practice could lead to certain problems; for example, after the design research has been carried out, the teacher is still responsible for the continued teaching.

Mathematics education researchers have highlighted a lack of classroom-based interventions that focus on teaching and teacher learning and also the lack of designbased studies promoting investigation in the classroom. This gap requires a shift in 
research focus from the learners to the teachers (Mariotti, Durand-Guerrier \& Stylianides, 2018). One way to approach teaching is to focus on teachers and the participation of teachers in order to understand how they communicate when designing tasks and teach theoretical concepts within a specific mathematical perspective. To this intention, studying the participation of teachers and the meaning that becomes negotiated (Wenger, 1998) in a specific mathematical content within a process may be central. When teachers play an active role, and the object of study is teachers' meaning-making of a specific algebraic perspective, the results can be a new, presumable, and challenging way to think about mathematics teaching in elementary school (Grade 1-6). In Grades 1-6 in Sweden (grundskola årskurs 1-6), it is not common to teach functional thinking in relation to patterns, thus making it particularly interesting to follow a design process that includes functional thinking because it deviates from a more traditional way of teaching. This also makes a reasonable argument for why the teachers must negotiate the meaning of this mathematical content.

The aims of this article are to shed light on the process when teachers participate as actors in educational design research focusing on generalizations in patterns and to elaborate on the consequences these challenges have for teachers in their learning process. What challenges do teachers face, and what opportunities arise when teachers negotiate the meaning of generalization in patterns in educational design research?

\section{Design research and the content in the intervention}

Educational design research provides for theoretical contributions and understanding of classroom phenomena as well as possibilities to develop classroom practice. A variety of educational design research and professional development programs are documented, named, and designed in a number of common ways, for example, developmental research (Gravemeijer \& van Eerde, 2009), classroom design studies (Stephan \& Akyuz, 2012) and professional development design studies (Cobb \& McClain 2001). Traditionally, educational design research involves the intervention and recurring cyclical processes of designing, teaching, and refining teaching experiments in a specific educational domain. 


\subsection{Focus in educational design research}

Educational design studies are conducted in diverse ways. Some research focuses on students' learning and learning activities (Stephan \& Akyuz, 2012), while others focus on teachers' learning in a design research process (Cobb \& McClain, 2001). Few design studies and interventions focus on teachers and teachers' learning in all phases of the design process - designing, teaching, and refining. In one study, classroom design research focusing on students' learning, also involves three practices that the teachers learned and identified when participating in an intervention: collaboration with other teachers, collaboration with the researcher, and learning from their reflections on their teaching (Stephan, 2015). Another study place teachers in the role of co-designer in the design process. Here the authors describe the teacher as a crucial person who goes from being an implementer to a co-designer (Konrad \& Bakker 2018).

Various methodologies can be implemented in educational design research. In this study, a teacher-focused classroom design study was used, which can be regarded as a classroom design study that focuses on teachers' learning instead of students' learning. Classroom design studies are characterized by researchers often collaborating with several mathematics teachers in a particular mathematical domain. Certainly, limitations in educational design studies have been identified, which Cobb, Jackson, and Dunlap Sharpe (2017) describe as "the lack of attention to the instructional practices of the teacher in the study" (p. 228). This quotation serves to further highlight the focus of the teacher and her practice.

Teachers' learning in educational design research

Educational design research is intended to produce relevant and usable theoretical knowledge that can be used in practice. However, research has yielded further questions in teacher development programs, such us, what have teachers actually learned and experienced in these programs (Sztajn, Borko \& Smith 2017)? Questions of what teachers have learned led to a greater understanding of teachers' difficulties to use and implement theoretical concepts from research in the teaching, which also falls in line with Cobb et al. (2017), among others. This is yet another reason why the teachers' learning is central in all phases in the design process. 


\section{Design Principles}

In educational design research, a theory is used to frame the content in the intervention. Normally, design research has recurring cyclical processes and uses, for example, hypothetical learning trajectories for a specific educational issue. These hypothetical learning trajectories are continuously revised and unfold in a local instruction theory in the predetermined educational area (Gravemeijer \& van Eerde, 2009). However, in this study, recurring cyclical processes are still used, but instead of hypothetical learning trajectories, Design Principles (DPs) identified from previous research are used as a theoretical frame (Greeno, 2006; McKenney \& Reeves, 2012). The DPs give the intervention a theoretical grounding, guide the intervention, and provide opportunities to understand a particular educational phenomenon (Greeno, 2006). The purpose was to develop a conceptual understanding of generalizations in patterns and functional thinking. In turn, this led to identifying DPs from previous research that has been essential for teaching generalization in patterns and functional thinking. The DPs can be considered similar to goals for teaching that will give theoretical ideas of the content, which students then have the opportunity to learn and develop.

\subsection{The mathematical content in the intervention}

One specific perspective of algebra and algebraic thinking has been chosen for this study - patterns in arithmetic sequences. Algebraic thinking in Grades 1-6 can be likened to mathematical reasoning or algebraic reasoning, and algebraic thinking is sometimes equated with early algebra (Blanton, Stephens, Knuth, Garidner, Isler \& Kim, 2015). In this study, algebraic thinking also means giving students opportunities to generalize and justify relationships among quantities. Therefore, generalization, patterns, and functional thinking are central in this article.

\section{Generalization}

Generalization is expressed as a key aspect of algebraic reasoning (e.g. Kieran 2004). The concepts of generalization are used in both everyday life and in mathematical contexts with a variety of explanations and meanings. According to Dörlfler (1991), generalizations in mathematics can be defined as both "an object and means of thinking and communication" (p. 63). In school mathematics, the object could be interpreted as the generalizations expressed in conventional symbols, and the thinking and communication could be likened to communicating and reasoning with 
generalizations expressed through a variety of representations.

The central elements of reasoning in school mathematics include activities such as exploration, conjecture, and justification. These concepts can be seen as activities in a cyclical process, such as the reasoning and proof cycle (NCTM 2008). Both conjecture and justification involve activities of logical thinking and general statements that make it possible to view and express mathematical structures, thus extending generalizations (Blanton, Stephens, et. al. 2015). However, research indicates that teachers and students' have difficulties understanding and working with generalizations (Stylianides \& Silver, 2009). Working with generalizations and pattern identification in teaching is embedded with difficulties, such as understanding the differences and the nuances that exist in pattern identification "in which cases can we trust a pattern without a need for further examination of particular cases” (p. 249). This quotation relates to empirical generalization and theoretical generalization empirical generalization can be described as generalizing from one situation to another, and theoretical generalizing is generalizing to an abstraction. Dörfler (1991) considers that some form of symbolic description, for example, letters, geometric illustrations or verbal stories, are needed to make theoretical generalizations. Teachers draw on different resources when teaching generalizing in mathematics, and according to Dörfler (1991), empirical generalization and theoretical generalization can be seen as problematic in mathematics teaching. One reason may be that mathematics as a science uses theoretical generalizing, whereas several general conceptions in both school mathematics and in real life use empirical generalizations as explanatory models. Dörfler (1991) highlights the importance of being aware of the mutual relationship between empirical and theoretical generalizations.

\section{Patterns and functional thinking}

One way to introduce generalization in elementary school is through teaching patterns and pattern identification. When working with patterns in general, opportunities for algebraic thinking develop (Blanton, Stephens, et. al. 2015; Mulligan, Cavanagh \& Keanan-Brown, 2012; Mulligan, Mitchelmore, English \& Crevensten, 2013). According to Kaput (2008), algebraic thinking involves two core aspects - making and expressing generalizations in symbol systems and reasoning with symbolic forms.

Studies suggest that neither mathematics curricula nor mathematics teaching may prepare students enough to transform from concrete arithmetic reasoning to abstract algebraic reasoning (Blanton, Stephens, et al., 2015; Kieran 2004). Therefore, the 
process of first-arithmetic-then-algebra is regarded by some as controversial, as the teaching in elementary school often includes both algebraic and arithmetic concepts (e.g., Blanton, Stephens, et al. 2015). One aspect of algebraic reasoning is functional thinking, which includes for example identifying a recursive pattern and describing the pattern in words, identifying a covariational relationship and describing the relationship in words, identifying the meaning of a variable used to represent a varying quantity, and constructing a coordinate graph (Blanton \& Kaput, 2004; Blanton, Stephens et al., 2015; Carraher \& Schliemann, 2015). According to Beckmann and Izsák (2015), understanding the relationship between two (or more) varying quantitates is central when working with functions and functional thinking. Beckmann and Izsák (2015) highlight the concept of the variable-parts perspective to express a proportional relationship and facilitate the identifying of functional relationships between two covarying quantities. This variable-parts perspective could explain how qualities can remain fixed even when quantities vary in a proportional relationship. Elementary students often meet unknown quantity with a missing fixed value (Blanton, Levi, Crites \& Dougherty, 2011); however, studies have shown that elementary students represent the functional relationship by using variable notation to represent the generalization (e.g., Blanton, Brizuela, Gardiner, Sawrey, \& NewmanOwens 2015; Blanton, Stephens, et al. 2015; Schliemann, Carraher, \& Brizuela, 2007). What is interesting in these studies is that the young students chose to use variable notation to denote the generalizations rather than tell a story with natural language to express the generalization.

One way to think about algebra in elementary school is expressed by Caspi and Sfard (2012), who relate school algebra and generalization to a meta-discourse of arithmetic, including numerical patterns, relationships, and quantitates. Caspi and Sfard (2012) point to the value of teaching algebra in students' daily practices in close relation to the students' understanding of informal arithmetic. The authors emphasize the importance of teaching and present parts of the algebraic thinking in several mathematical issues in elementary school before students meet formal algebra in upper secondary school. Caspi and Sfard (2012) emphasize the importance of acknowledging the close relationship between formal algebra and the students' understanding of arithmetic thus, "helping the students closing the gap between their spontaneous meta-arithmetic and the formal algebra taught in school" (p. 21). This quotation in particular, points to unresolved issues in teaching algebra in elementary school, namely teachers' challenges to give students the opportunities to understand 
formal algebra. The spontaneous meta-arithmetic and the formal algebra, as well as Dörfler's (1991) interpretation of a mutual relationship between empirical generalization and theoretical generalization, fall somewhat in line with what has emerged in research -that young students prefer to use variable notation rather than natural language to express generalizations.

\subsection{Algebra and functional thinking in the Swedish context}

Mathematics teaching in Sweden is characterized by textbook use, as a large part of the teaching is guided by a textbook (Johansson 2006). In Swedish curriculum materials (National Agency of Education, 2017) for elementary school, mathematical reasoning is one competency that students should be given the opportunity to develop through a variety of mathematical content. The concepts of generalizing are not mentioned in the Swedish national curriculum materials for elementary school; instead, patterns and proportional relationships are conceptualized as two separate mathematical themes in the materials (National Agency of Education, 2017). These themes are often treated separately in the Swedish classroom and textbooks, and the topic of proportional relationships in elementary school Grades 1-6 (Swedish grundskola årskurs 1-6) is often used to explain the concepts of "double" and "a half" and is rarely used as functional thinking in the lower grades. Functional thinking and the equation for linear function are first described in Grades 7-9 in curriculum materials (National Agency of Education 2017). Carraher, Schliemann, and Schwartz (2008) have also pointed out the lack of functional relationships in elementary school: "It is nothing short of remarkable that the topic of functions is absent from early mathematics curricula" (p. 265).

\section{Overview of the study}

The study outlined in this article is part of a project entitled Mathematical reasoning in algebra in elementary school - The role of the teacher in an educational design research process. In this article, one aspect of mathematical reasoning is central generalizations - and generalizations in a specific algebraic perspective, namely, patterns and functional thinking. In this study, conducting educational design research using teachers as actors and involving teachers in the entire design process was a way to explore the challenges that teachers encountered when designing, teaching, and refining theoretical concepts related to generalizations in patterns. 


\subsection{Theoretical framing}

When focusing on teachers and their communication relating to generalizations in teaching patterns, theoretical frames that visualize teachers' learning were necessary. From the perspective of Communities of Practice, $(\mathrm{CoP})$, learning is explained as a process in which participants engage in social practice (Wenger, 1998). Therefore, learning can be interpreted as participants' changed participation and changed communication about a mutual engagement. The process involving participants' meaning-making and reification is an active dynamic process, and in a process, the participants' shared repertoire changes. In this case, the participants negotiate the meaning of the content in the DPs, which means the teachers in the study communicate and relate generalizations about patterns and functional thinking to their teaching.

Based on a part of Wenger's (1998) learning theory, the idea of learning during boundary crossing was central in this study. In this article, the intervention will be seen as a boundary encounter in the teachers' learning. In line with $\mathrm{CoP}$ and Wenger, various boundary encounters can happen in a CoP, for example, a conversation between two participants from two different communities involving some sort of boundary. Another way to enrich the boundary encounter in the community is to visit another practice to gain some exposure. Boundary encounters consist of boundary objects. Wenger (1998) describes these boundary objects as new and unknown objects for the participants' in the community, for example, artifacts, terms, or concepts. Thus, the boundary objects could be a way to organize the communication and learning in a CoP. In this case, the intervention can be comparable to a boundary encounter - the participants meet theoretical concepts about generalizing in pattern and functional thinking. These theoretical concepts of the DPs' are comparable to the boundary objects as unknown concepts introduced in the teachers' learning. In the design process, the teachers participate as actors and have possibilities to negotiate the meaning of the DPs related to their teaching.

To summarize, Wenger's (1998) notions of boundary crossing, boundary encounter, and boundary objects are used to explore and exemplify the challenges and opportunities that teachers face in a design process when they negotiate the meaning of generalizations in patterns. For this purpose, Wenger's analytical concepts of boundary-crossing, and boundary objects are applied as well as the negotiation of meaning and the participants' changed repertoire about generalizations in patterns. 


\subsection{Methodology}

Conducting a teacher-focused classroom design research using teachers as actors throughout the design process was a way to explore the challenges that teachers encounter when designing, teaching, and refining theoretical concepts related to generalizations in patterns. The purpose of the intervention is to support the conceptual understanding of generalizations in patterns and functional thinking as well as to support teachers' learning in the process. However, the main purpose of this article is to visualize the challenges and opportunities that occur in educational design research. Therefore, two perspectives are central in this study - that of the teachers as they participate as actors throughout the entire process and that of a study situated in the entire design process. The red field in Figure 1 illustrates where the study is situated. The three phases - which symbolize designing, teaching and refining overlap and are inevitably intertwined.

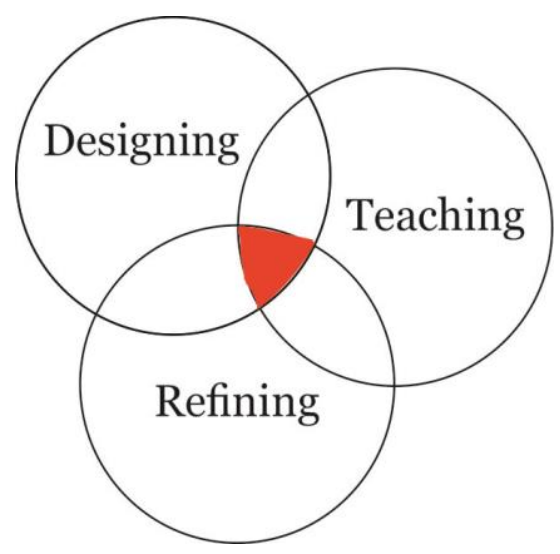

Figure 1. The red field represents where this study is situated.

Teachers as participating actors throughout the entire design process

In addition to the author, three mathematics teachers, one from Grade 1 and two from Grade 6, participated and collaborated in three recurring design cycles. The three teachers were selected from a previous study on teachers' meaning-making about mathematical reasoning and mathematical communication (Sterner, 2015). As a result, the participants and their community can already be seen as an incorporated CoP, according to Wenger (1998). Wenger explains that a CoP includes the participants having a shared way of engaging and doing things together, for example, a quick setup of a problem to be discussed and sustained mutual relationships that 
may be harmonious or conflictual.

The study took place over a period of nine months (Fig. 2) and three recurring design cycles were carried out. Figure 2 shows a timeline of the entire design study, which illustrates each individual teacher's process in the design study. The three half circles illustrate each of the three teachers' teaching, and the line underneath illustrates the designing and refining phases. This article will focus solely on designing and refining phases. Therefore, the teaching will be used to exemplify challenges that arise from the teaching and what opportunities and consequences these challenges will have for the continued design process.

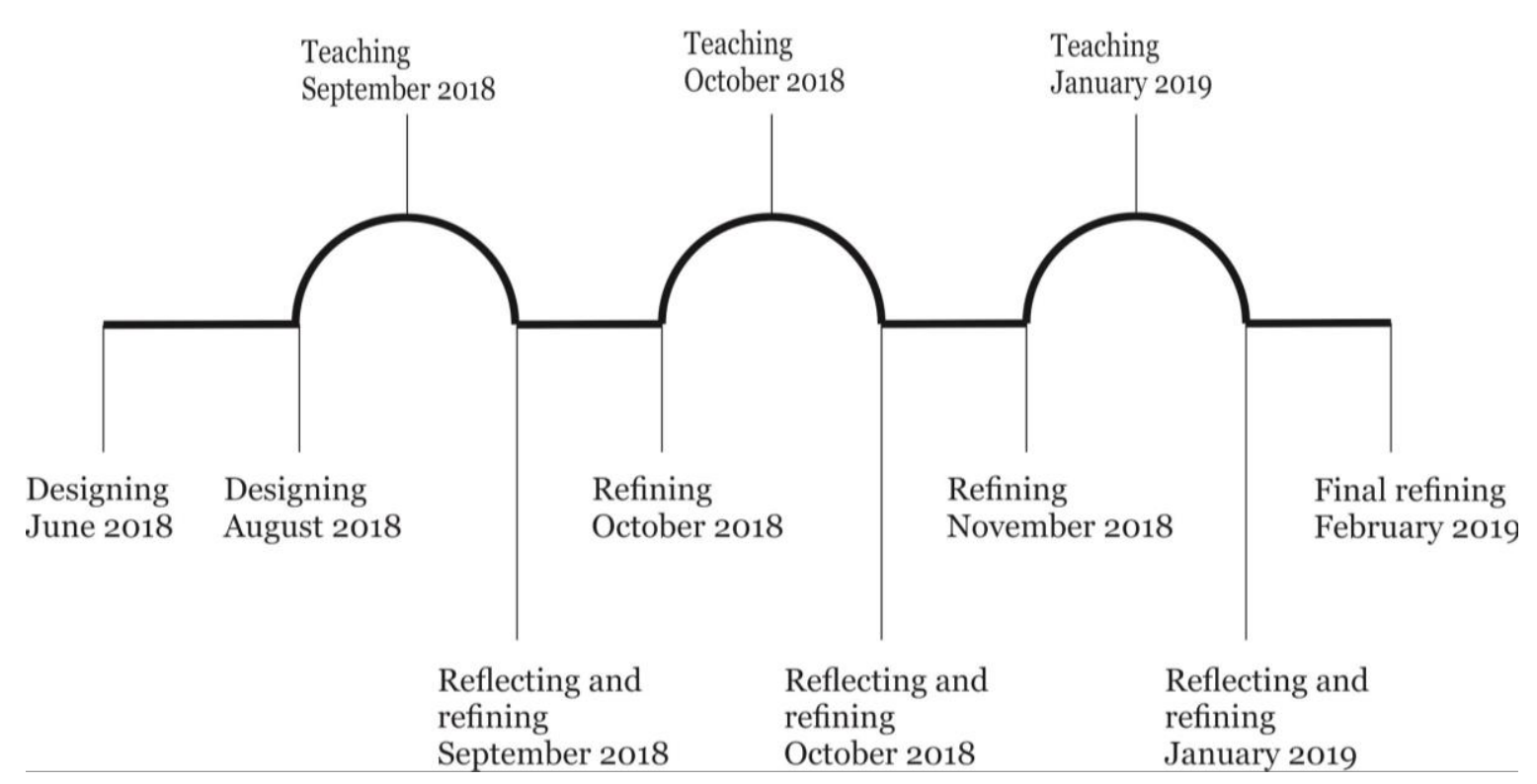

Figure 2. Timeline of the entire study.

Teacher-focused classroom design research

To take advantage of what has emerged in previous research on generalizations and patterns, DPs were chosen to focus on the mathematical content in the intervention. DPs are formulated based on previous research; however, the teaching is traditionally done in a Swedish context, which the intervention needed to take into account. These DPs frame and guide the intervention as well as give theoretical ideas of the content that the students have opportunities to learn and develop in the teaching. The two DPs used in this study were created as a goal for teaching:

DP1: The students should be given opportunities to identify a pattern, structure the pattern and generalize the pattern (Mulligan et al., 2013; Stylianides \& Silver, 2009). 
DP2: The students should be given opportunities to work with algebraic reasoning, including functional thinking and proportional relationship and determining relations between two or more varying quantities (Beckman \& Izak, 2015; Blanton, Stephens, et al., 2015; Blanton \& Kaput, 2004).

The site and the participants

The participating teachers work at three different schools in a mid-size town in Sweden. Three recurring cycles were carried out, and five meetings with teachers were carried out - two meetings to design activities before teaching and one session after completing the design research (Fig. 2). The researcher (the author) worked closely and collaborated with the teachers in the design and refining phases and acted as an observer in the teaching. After teaching, the teacher and the author spent 20-30 minutes reflecting and refining.

Each common meeting was two and a half hours long, and all the participants participated in each meeting. The purpose of these common meetings was to create and develop an understanding of the theoretical concepts in the DPs as well as design and refine the teaching that included these theoretical concepts. The individual reflection directly after the teaching was conducted in order to get the teachers' immediate thoughts and ideas in connection with what had just happened in the classroom. These reflections were used in the forthcoming common refining phase.

\section{Data collection and the selected data}

The data collection included video recordings from various parts of the design process: five common meetings from the design and refining phases and fifteen lessons consisting of twelve from Grade 6 and three from Grade 1. Other data material includes copies of student work, field notes from the classroom observations, and tape recordings of reflections with the teachers directly after teaching.

The empirical data analyzed in this study are primarily the three teachers' communication about generalizations in patterns and the actions they took related to generalizations. Teaching sequences from Grade 6 were used to exemplify activities and tasks related to the DPs. These sequences also influence the ongoing discussions in the common refining phase. The selected data were based on empirical data grounded on what challenges and opportunities teachers meet when they negotiate the meaning of generalizations in patterns in a design research project as well as in teaching. 


\section{Data analysis}

In this study, the DPs are seen as a theoretical framework for the intervention and as goals for teaching. In the analysis, Wenger's (1998) theoretical frame of boundary objects revealed the teachers' meaning-making and understanding of generalizations in patterns based on the content of the DPs. Wenger's frame makes it possible to make visible how the teachers' shared repertoire of DPs changed in the teachers' discussions during the process as well as in the teaching. Focusing on boundary objects also made visible how the DPs were transformed from theoretical concepts to activities in the classroom and for the teaching and furthermore to refining the activities and the teaching.

\section{Ethical consideration}

The intention was not to generalize the results but rather to exemplify the challenges and opportunities of an educational teacher-focused classroom design research and give an understanding of what those can accomplish. Thus, the actual number of teachers is not relevant to this study. However, ethical considerations have to be made throughout the entire research process, from the first planning of the study to the last report (Goodchild, 2011). Both external and internal issues (Floyd \& Arthur, 2012) have been important in this study. Internal issues include taking into consideration the teachers' and the students' participation as well as the chosen content in the design process. Therefore, it was important that I ask myself certain questions, for example, in what way can theoretical concepts from the mathematics research field and the competencies from mathematics teachers' practice interact? And in what way can our different competencies and experiences be visible and operated in the process? And what mathematical content is relevant and possible in this intervention? The external ethical issues regulated for research provided by the Swedish Research Council (2017) were followed, and both guardians and students gave consent for participation. The students were given verbal information about the intervention, and both the students and the students' guardians were given written information about the study and had approved participation in line with the ethical guidelines.

The context in which the study took place

The observed teachers' teaching was similar both in terms of structure and the teaching situation, although some differences naturally arose. To demonstrate the context of this study, Irma's teaching serves as an example, as it was broadly 
representative of the approach adopted by all three teachers, particularly the two Grade 6 teachers. Irma began the sequence of teaching patterns with multiple approaches when introducing patterns, particularly those to do with growing arithmetic sequences. She used various teaching methods and a variety of materials to illustrate patterns, for example, matches, cubes, and pictures. In Irma's teaching, several representations were revealed to depict the patterns; for example, pictures, tables, or students' stories.

Two mathematical tasks that were taken from other studies were particularly interesting in the intervention. One task was used to exemplify direct proportionality. All the teachers worked with a task concerning a certain number of dogs and the corresponding number of tails, ears, and legs to illustrate the use of independent and dependent variables. The students had to represent the number of tails, ears, and legs in different ways, for example, pictures, tables, diagrams, and graphs. The works of Blanton and Kaput (2004) and Mulligan et al. (2013) inspired this task, which was used to understand direct proportionality.

The other especially interesting task in the design process was a pattern illustrating "the cube train" (see Figure 3). The cubes represented a train with an engine and one or more train cars. The red cubes illustrated the engine, and the green cubes illustrated the first train car (Fig. 3). This task, in which the cubes illustrated a growing arithmetic sequence, was inspired by Beckman (2018): "The first train is made from a 4-cube engine and one 5-cube train car. Each subsequent train is made by adding one more 5 -cube train car" (p. 415).

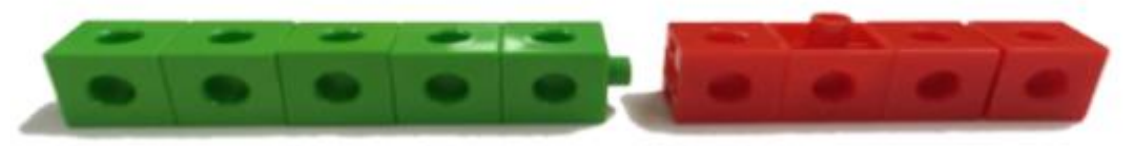

Figure 3. Image of the "the cube train", which represents a growing pattern in an arithmetic sequence (Beckman 2018, p. 415).

This cube train task created opportunities to talk about differences in direct proportionality. For example, in the previously mentioned task, the number of dogs and legs is represented by $y=4 x$. The cube train task offered possibilities to talk about and uncover the $m$-value or the oth position (Beckman 2018). 
The two tasks, the dogs and the train, were used to give students opportunities to use different representations to explain and find the generalizations. The tasks were chosen to clarify the $m$-value and shed light on the slope of the graph. Furthermore, the tasks created opportunities to talk about independent and dependent variables, as well as how the quantities corresponded. The overall aim of working with these tasks was to give opportunities for the students to work with and develop an understanding of generalization by working with patterns in arithmetic sequences.

\section{Results}

The results are presented based on the challenges and opportunities that arose in the teachers' meaning-making about generalizations in the design process. When the teachers worked as actors in the design process and negotiated meaning about generalization in patterns, five themes of challenges were revealed in the analysis: working with the unknown, understanding what DPs mean in the classroom, questioning taken-for-granted views, the need for mathematical language and finally starting to teach with the generalizations. The challenges were proven to lead to opportunities for developing teaching. These themes will be presented in the teachers' negotiation of meaning about generalizations in patterns in relation to their teaching.

\subsection{Working with the unknown}

The intervention and the DPs were found to be challenging in several ways. In the initial stage of the discussions in the design phase, the teachers clearly stated that they did not want to work with functional thinking or proportional relationships when teaching patterns. The teachers questioned the relevance between the two DPs and could not see the importance of working with two "totally different" contents, patterns, and functional thinking. They asked several times, "Why are we using linear equations together with patterns? ... we don't understand the reason.” The teachers negotiated the meaning and tried to understand the theoretical concepts in DP1. One of the challenges during the process turned out to be working against the unknown, as in the boundary objects. These boundary objects (DP1 and DP2) turned out to create both tension and opportunities in the teachers' discussions to develop something that was not previously known in their teaching. Working with functional thinking in relation to patterns was a new and previously unknown way to think about mathematical content patterns and generalizations. 


\subsection{What do DPs mean for the classroom?}

The next stage of the discussion in the design phase before the teaching consisted of teachers' meaning-making about the DP1. The teachers negotiated the meaning of each of the concepts in the DP1 and asked questions such as, what does it mean to identify? What does it mean to structure? And what does it mean to generalize a pattern?" The teachers' discussions focused on practical teaching ideas related to the DP1 - identifying, structuring and generalizing patterns. In the teachers' initial discussion, the three theoretical concepts were discussed in close relation to the teaching practice. In particular, the discussion focused on different representations in relation to identifying, structuring and generalizing. In the teachers' meaningmaking, identifying a pattern was often associated with students' stories. Structuring patterns were often associated with students' pictures, tables, or conversations when the students used different materials, such as matches or cubes, and these materials were put into piles illustrating the pattern related to the training task (Fig. 3). In the teachers' negotiation of meaning, similar questions and assertions arose: "Is it possible to structure a pattern and equate it as a generalization?" and "Every time we added one more cube train car, we got 5 more cubes, and the 4-cube engine only happens once. It's the same is for the whole train." With regard to the teachers' discussion, in the initial stage, the three theoretical concepts in DP1 were understood as three different representations; later, they negotiated the meaning and talked about generalization as something that could be represented in different ways. Nevertheless, there was resistance to discussing the content in DP2; however, opportunities to discuss DP2 arose when the teachers talked about the task with the train. The teachers wanted to design similar tasks with an equally clear $m$-value.

\subsection{Questioning taken-for-granted views}

It became visible in the teaching that generalizing patterns could be represented in different ways, like identification in a story or a structured table as well as in general formula. The teachers talked about the students and their use of different representations to finally arrive at the general formula. In the end, the teachers were all in agreement that generalizing a pattern with a general formula would be the final, optimal understanding for students. In other words, a generalization was equated to a general formula. This statement was agreed with by the teachers until they tried to challenge the students' understanding and ask for justification and explanation of the 
general formula.

One of the tasks the teachers returned to several times was the growing pattern illustrated with a train: "made from a 4-cube engine and one 5-cube train car" (Fig. 3). In the teaching, the teachers gave the students possibilities to talk about their empirical stories and the patterns in the arithmetic sequence, for example, "Every sequence is increased by five cubes" or "The number of train cars five times and add four." From this and similar stories, many Grade 6 students could use the language and generalize as well as write a general formula. Some of the students needed a table to structure the information before they see and could express the growing pattern. The teachers employed practical ideas from the discussions in which they had previously participated, for example, those from earlier discussions in which the teachers had agreed to use variable notations and a general formula that would represent the best generalizations and the final state of the activity.

In teaching, the teachers faced unexpected reflections from the students. Irma tried to challenge the students and ask them to explain and justify what $5 x$ in this general formula $y=5 x+4$ signified and symbolized. At that moment, few students could justify and explain the generalized formula, and most of the students did not have the words to talk about, what is behind the generalized formula. Later in the forthcoming reflection in the design process, the teachers discussed what they experienced during the teaching. They talked about the frustrating and eye-opening moments in their teaching. As teaching with patterns often includes several representations with justifications, they had previously taken-for-granted that the general formula with variable notation was the final representation and, therefore, no explanation would be needed for the formula.

\subsection{Need for mathematical language}

A change in the teachers' communication arose, as the discussions changed to curiosity and thinking about opportunities to use functional thinking to help the students understand and explain the general formula. The meaning-making in their discussions led back to functional thinking, the DP2, and the task about the number of dogs relating to their number of tails, ears, and legs. The teachers also designed other tasks, such as, "What about other animals, like spiders with eight legs?" In the design and reflection phases, the teachers' meaning-making about generalizations changed from seeing the generalized formula as the final representation to focusing 
on the generalized formula as one representation and functional thinking as a possibility to understand and talk about generalizations.

Working with linear functions gave the students as well as the teachers possibilities to talk differently about the generalizations and understand what is behind the generalized formula. Teaching linear equations and functional thinking was new and unknown for the teachers regarding teaching generalizations in patterns and arithmetic sequences. The teachers recognized new challenges, such as several unknown words that are necessary for working with functional thinking and proportional relationships, for example, "coordinates", "independent and dependent variables", "graphs," and "linear equations". This new unknown world brought with it a negotiation about the meaning of these worlds and a need for mathematical language in both the teachers' discussions and in the classroom.

At the end of the process, some students, as well as the teachers, said, "I can see the generalized formula in a graph." The teachers discussed the importance of having tasks with a clear $m$ - value. Here the teachers often returned to the exercise with the train, where the engine could be seen as a clear illustration of the $m$ - value.

\subsection{Start to teach with the generalizations}

In the last refining phase, the teachers discussed the students' co-variational thinking and how they use natural language to describe how the quantities corresponded. The teachers discussed the importance of the $m$ - value, the constant of proportionality $(k)$, and the slope of the graph. They discussed how some students had the ability to see, understand, and describe the general formula with natural language. Therefore, the teachers wanted to design teaching and activities where students start with the general formula. The students relied on using natural language to talk about the slope, the independent and dependent variable, and the $m$ - value, and then used different representations to show the generalization.

The teachers designed different tasks and activities to make it possible for the students to use different representations to justify the generalized formula. These activities helped the teachers talk about different patterns in relation to generalizations. The teachers used the general formula given in the aforementioned train task: 
We know this is a general formula $y=5 x+4$ to describe the growing pattern in the cube train task. Can we illustrate the formula in another way? What does the start-value mean $(m-$ value)? What are the differences between these equations: $y=4 x, y=4 x+2, y=6 x+2$, and $y=6 x+4$ ?

The students justified the difference, for example, between $y=4 x$ and $y=4 x+2$ and talked about the $m$ - value. The teachers discussed the students' competence in reasoning about two generalized quantities that are related, in that the ratio of one quantity to the other is invariant. One of the teachers said, "Nowadays, some students recognize a pattern of direct matches when they encounter a general formula, or a see a graph.”

To summarize, this case visualizes the importance of the involvement of teachers in all phases - the teachers are faced with challenges in the classroom that have consequences for the conversation in the design and refining phase. It seems reasonable to infer that the teachers learn new things about generalizations; however, the teachers changed and talked differently about generalizations in patterns as well as changed and developed their teaching in generalizations. Therefore, functional thinking supports the teachers as well as the students when talking about the generalizations.

\section{Discussion}

The results of my study give insight into what can be gained from a teacher-focused classroom design research. The results show teachers involved in a complex process of meaning-making in the process of understanding teaching and learning generalizations in patterns in algebra.

In the study, the teachers participating as actors in educational design research faced various challenges in the process. These challenges were sometimes met with resistance; however, they gave rise to consequences that appear to drive the teachers' process of change and development. Therefore, meeting these challenges seemed to be a prerequisite for opening up opportunities; for example, certain challenges were revealed when teachers designed activities and teaching generalizations in patterns in arithmetic sequences. The teachers realized that the students had difficulties in justifying a generalized formula. In the design process, the teachers also became aware that functional thinking and the linear equation could create opportunities to talk about what is "behind" a generalized formula. The teachers found that teaching 
the concept of functional thinking and the linear equation in close relationship with patterns could facilitate students' understanding of generalizations. Previous studies also support these findings (e.g., Blanton \& Kaput, 2004; Blanton, Brizuela, et al. 2015; Blanton, Stephens, et al., 2015). In this particular case, the teachers refer to functional thinking as something that creates opportunities to discuss and justify the generalized formula, and this led to a change in the teachers' awareness of generalizing. Generalization, as a concept beyond the more generalized formula and variable notation, is related to what has been found in previous studies - that elementary students use variable notation rather than natural language to express a generalization (Blanton, Brizuela, et al. 2015; Blanton, Stephens, et al., 2015). This falls in line with both Caspi and Sfard (2012), who claim the importance of letting young students use a spontaneous arithmetic language to understand the formal algebra, and it also falls in line with Dörfler (1991), who advocates a mutual relationship between theoretical and empirical generalizations.

This teacher-focused classroom design research had led to certain insights. This research is complementing traditional educational design research, and the chosen methodology shows the importance of having teachers as participating actors throughout the entire process. The teachers were met with surprising challenges in their teaching; for example, they challenged the students to justify what is behind a general formula. These challenges had consequences for the ongoing discussions in the design process, and as a result, the participating teachers changed how they talk about generalization. This shows that teachers as participating actors in all phases in educational design research can contribute to what are regarded as missing links in some design researches, both in terms of interweaving research findings and practice (Marotti et al. 2018) and in terms of the focus on instructional practice of the teacher (Cobb et. al. 2017).

Another reflection is that the teachers showed greater resistance to working with functional thinking than I had expected. However, it is important to note that, at the end of the process, the teachers changed their mind and talked about functional thinking as a new representation or a new tool for discussing generalizations in patterns with students. The teachers described their learning and the students learning about generalizations in relation to patterns as an "aha! experience" patterns and the linear equation made for a new and an unexpected combination.

The challenges and the resistance in the process created opportunities, thus leading to the argument that challenges may be necessary for developing teaching. 
Although the DPs are available, the results indicate that the teachers need to be challenged and negotiate the meaning of the DPs. This could be the consequence of the teachers having certain doubts in relation to the current DPs, or it may be an indicator of the more general importance of being challenged in order to develop new practices. The result supports that some forms of boundary objects (Wenger, 1998) appear necessary for a design research process. The analytical frame (Wenger, 1998) and the theoretical frame for the intervention - the DPs - made it possible to shed light on these three teachers' learning about teaching patterns with a focus on generalizations.

\section{References}

Beckmann, S. \& Izák, A. (2015). Two perspectives on proportional relationships: Extending complementary origins of multiplication in terms of quantities. Journal for Research in Mathematics Education 46, 17-38.

Beckmann, S. (2018). Mathematics for elementary teachers (5th ed.). Boston, MA: Pearson. Blanton, M. \& Kaput, J. (2004). Elementary grades students' capacity for functional thinking. Proceedings of the 28th Conference of the International Group of Psychology of Mathematics Education, 2, 135-142.

Blanton, M., Brizuela, B. Gardiner, A. Sawrey, K. \& Newman-Owens, A. (2015). A learning trajectory in 6-years-olds' thinking about generalizing functional relationships. Journal for Research in Mathematics Education, 46(5), 511-558.

Blanton, M., Levi, L., Crites, T., \& Dougherty, B. (2011). Developing essential understanding of algebraic thinking for teaching mathematics in Grades 3-5. In R. M. Zbiek (Ed.), Essential understanding series. Reston, VA: National Council of Teachers of Mathematics.

Blanton, M., Stephens, A. Knuth, E., Gardiner, A. M., Isler, I., \& Kim, J. S. (2015).. (2015). The Development of Children's Algebraic Thinking: The Impact of a Comprehensive Early Algebra Intervention in Third Grade. Journal for Research in Mathematics Education, 46, 39-87.

Carraher, D. W., \& Schliemann, A. D. (2015). Powerful ideas in elementary school mathematics. In L. D. English \& D. Kirshner (Eds.). Handbook of international research in mathematics education (3rd ed., 191-218). New York: Taylor \& Francis.

Carraher, D. W., Schliemann, A. D. \& Schwartz, J. L. (2008). Early algebra is not the same as algebra early. In J. Kaput, D. Carraher, \& M. Blaton, (Eds.), Algebra in the early grades (235-272). Mahwah, NJ: Lawrence Erlbaum/Taylor \& Francis Group; Reston, VA: National Council of Teachers of Mathematics.

Caspi, S. \& Sfard, A. (2012). Spontaneous meta-arithmetic as a first step toward school algebra. International Journal of Educational Research, 45-65.

Cobb, P., Jackson, K. \& Dunlap Sharpe, C. (2017). Conducting Design Research Studies to Investigate and Support Mathematics Students' and Teachers' Learning. Research on the Teaching and Learning of Proof: Taking Stock and Moving Forward. In J. Cai (Ed.) Compendium for research in mathematics education. National Council of Teachers of Mathematics, 208-233. 
Cobb, P. \& McClain, K. (2001). An approach for supporting teachers' learning in social context. In F. L. Lin \& T. Cooney (Eds.), Making sense of mathematics teacher education (207-232). Dordrecht, The Netherlands: Kluwer Academi.

Dörfler, W. (1991). Forms and means of generalization in mathematics, in A. J. Bishop (ed.), Mathematical Knowledge: Its Growth through Teaching, Kluwer Academic Publishers, Dodrecht, 63-85.

Floyd, A. \& Arthur, L. (2012). Researching from within: external and internal ethical engagement. International Journal of Research \& Method in Education, 35(2), 171-180.

Goodchild, S. (2011). Classroom research: impact and long term effect versus justice, liberation and empowerment? In L.O Björkvist \& A. Röj-Lindberg (Eds.). Long-Term Research in the Didactics of Mathematics and Science. (9-25). Åbo: Faculty of Education. Åbo Akademi University.

Gravemeijer, K. \& van Eerde, D. (2009). Design Research as a Means for Building a Knowledge Base for Teachers and Teaching in Mathematics Education. The Elementary School Journal, 5, 510-524.

Greeno, J. G. (2006). Theoretical and Practical Advances through Research on Learning. In J. L. Green, G. Camilli \& P. B. Elmore (Eds.) Handbook of Complementary Methods in Education Research (795-822). Washington, DC: American Educational Research Association.

Johansson, M. (2006). Teaching Mathematics with Textbooks a Classroom and Curricular Perspective. Doctoral dissertation. Luleå: Luleå University of Technology Department of Mathematics.

Kaput, J. J. (2008). What is algebra? What is algebraic reasoning? In J. J. Kaput; D. W: Carraher, \& M. Blanton (Eds.), Algebra in the early grades (5-17): Mahwah, NY: Lawrence Erlbaum/Taylor \& Francis Group; Reston, VA: National Council of Teachers of Mathematics.

Kieran, C. (2004). Algebraic Thinking in the Early Grades: What Is It? The Mathematics Educator. 139-151.

Konrad, U. \& Bakker, A. (2018). From implementer to co-designer: A teacher's changing role in a design research project. In A. Bakker (Ed.) Design Research in Education A Practical Guide for Early Career Researchers (246-254). Oxon, UK: Routledge.

Mariotti, M. A., Durand-Guerrier, V., Stylianides, G. J. (2018). Argumentation and proof. In T. Dreyfus, M. Artigue, D. Potari, S. Prediger \& K. Ruthven (Eds.), Developing research in mathematics education. Twenty years of communication, cooperation and collaboration in Europe (75-89). Oxon, UK: Routledge.

McKenny, S. \& Reeves, T. (2012). Conducting Educational Design Research. London: Routledge. Mulligan, J., Cavanagh, M., Keanan-Brown, D. (2012). In B. Atweh, M. Goos, R. Jorgensen \& D. Siemon, (Eds.). Engaging the Australian National Curriculum: Mathematics -

Perspectives from the Field. Mathematics Education Research Group of Australian (47-70).

Mulligan, J., Mitchelmore, M. C., English, L. D. \& Crevensten, N. (2013). Reconceptualizing Early Mathematics Learning: The Fundamental Role of Pattern and Structure. In L. D. English \& J. T. Mulligan (Eds.) Reconceptualizing Early Mathematics Learning, Advances in Mathematics Education, New York: Springer.

NCTM (2008). Navigating through reasoning and proof in Grades 9-12. National Council of Teachers of Mathematics Reston, VA: NCTM.

National Agency for Education (2017). Curriculum for the primary school, preschool class and leisure time centre 2017. Stockholm: National Agency for Education. 
Schliemann, A. D., Carraher, D., \& Brizuela, B. M. (2007). Bringing out the algebraic character of arithmetic: From children's ideas to classroom practice: Mahwah: Lawrence Erlbaum and Associates.

Stephan, M. L. (2015). Conducting classroom design with teachers. ZDM - Mathematics Education, 47, 905-917.

Stephan, M., \& Akyuz, D. (2012). A proposed instructional theory for integer addition and subtraction. Journal for Research in Mathematics Education, 43(4), 428-464.

Sterner, H. (2015). Problematisera "görandet", Lärares lärande om kommunikation och resonemang i matematikundervisningen $i$ en organiserad praktikgemenskap. Licentiat Dissertation. Växjö: Linnaeus University.

Stylianides, G. J. \& Silver, E. A. (2009). Reasoning-and-Proving in School Mathematics, The Case of Pattern Identification. In D. A. Stylianou, M. L. Blanton \& E. J. Knuth (eds.), Teaching and learning proof across the grades: A K-16 perspective. New York, NY: Routledge.

Swedish Research Council (2017). God Forskningssed. Stockholm: Vetenskapsrådet.

Sztajn, P., Borko, H. \& Smith, T. M. (2017). Research on Mathematics Professional Development. In J. Cai (Ed.) Compendium for research in mathematics education. National Council of Teachers of Mathematics (793-823).

Wenger, E. (1998). Communities of Practice: Learning, Meaning, and Identity (Learning in Doing: Social, Cognitive and Computational Perspectives). Cambridge: Cambridge University Press. https://doi.org/10.1017/CBO9780511803932 